\title{
Effect of temperature on production of okadaic acid, dinophysistoxin-1, and pectenotoxin-2 by Dinophysis acuminata in culture experiments
}

\author{
Takashi Kamiyama ${ }^{1, *}$, Satoshi Nagai ${ }^{1}$, Toshiyuki Suzuki ${ }^{2}$, Kazuyoshi Miyamura ${ }^{3}$ \\ ${ }^{1}$ National Research Institute of Fisheries and Environment of Inland Sea, Maruishi 2-17-5, Hatsukaichi, Hiroshima 739-0452, \\ Japan \\ ${ }^{2}$ National Research Institute of Fisheries Science, 2-12-4 Fukuura, Kanazawa, Yokohama, Kanagawa 236-8648, Japan \\ ${ }^{3}$ Fisheries Research Institute, Oita Prefectural Agriculture Forestry and Fisheries Research Center, 194-6 Tsuiura, Kamiura, \\ Saeki, Oita 879-2602, Japan
}

\begin{abstract}
We cultivated Dinophysis acuminata, a mixotrophic dinoflagellate causing diarrhetic shellfish poisoning worldwide, at different temperatures by providing a mixotrophic ciliate Myrionecta rubra as a food source. We examined the effects of temperature on growth rates and monitored production of the toxins okadaic acid (OA), dinophysistoxin-1 (DTX1), and pectenotoxin-2 (PTX2) using liquid chromatography-tandem mass spectrometry. Cell densities of D. acuminata increased at temperatures of $10,14,18$, and $22^{\circ} \mathrm{C}$, and the mean specific growth rates during the exponential growth phase were higher at higher temperatures $\left(0.14\right.$ to $\left.0.28 \mathrm{~d}^{-1}\right)$. The concentration of all toxins increased as cell densities increased. The mean cellular PTX2 content during the exponential growth phase was greater at lower temperatures, but clear differences in the other toxin concentrations in relation to temperature were not observed. The cellular content of OA and DTX1 significantly increased during the exponential growth phase at all temperatures except at $10^{\circ} \mathrm{C}$ for $\mathrm{OA}$, whereas that of PTX2 did not significantly increase at temperatures greater than $10^{\circ} \mathrm{C}$. Cellular toxin production rates temporarily increased at or just before the end of the exponential growth phase at 14,18 , and $22^{\circ} \mathrm{C}$, and the mean rates for OA production over the entire incubation period were higher at higher temperatures. Our results indicate that increasing temperature generally stimulates toxin production in $D$. acuminata populations due to an increase in cell density, but cellular content and production rates of OA and PTX2 in response to temperature differ and are influenced by growth phase.
\end{abstract}

KEY WORDS: Dinophysis acuminata - Growth rate - Temperature - Diarrhetic shellfish poisoning · Myrionecta rubra · Okadaic acid · Dinophysistoxin-1 · Pectenotoxin-2

Resale or republication not permitted without written consent of the publisher

\section{INTRODUCTION}

Several species within the dinoflagellate genus Dinophysis are the cause of bivalve contamination with toxins causing diarrhetic shellfish poisoning (DSP) and with lipophilic toxins (Hallegraeff \& Lucas 1988, Hallegraeff 1993, Quilliam et al. 1993); this results in serious economic losses to shellfish culture industries worldwide (Yasumoto et al. 1985, Della Loggia et al. 1993).

The population dynamics of the causative species and their cellular toxin content are important factors in the nature and magnitude of bivalve contamination. Information on abundance, seasonal distribution, and toxicity of several Prorocentrum species (potential DSP toxin producers) has been reported (Ten-Hage et al. 2000, Foden et al. 2005, Cruz et al. 2006, Maranda et al. 2007a,b). In addition, field observations on the population dynamics of Dinophysis species have been carried out in various areas (Koike et al. 2001, Nishitani et al. 2002, 2005, Lindahl et al. 2007).

The toxin content of Dinophysis acuta and D. acuminata in natural populations varies spatially and tempo- 
rally (MacKenzie et al. 2005, Lindahl et al. 2007). The toxin content of Dinophysis spp. can change markedly over an investigation period (Suzuki et al. 1997, Miyazono et al. 2008), and nontoxic D. acuminata has been observed (Hoshiai et al. 1997). Little is known, however, about the cellular dynamics of Dinophysis toxin production, and factors influencing toxin variations have not been examined due to the inability to culture Dinophysis spp.

Since the first successful cultivation of Dinophysis acuminata by Park et al. (2006), physiological characteristics of other Dinophysis species from laboratory culture experiments have been reported (Kim et al. 2008, Nagai et al. 2008, Nishitani et al. 2008a,b, Riisgaard \& Hansen 2009). As a result, potential growth rates of $D$. acuminata, D. caudata, D. infundibulus, and $D$. fortii have been clarified, and the effects of prey concentration and light condition on the growth of $D$. acuminata have been demonstrated (Kim et al. 2008, Riisgaard \& Hansen 2009), although other environmental factors influencing the growth of Dinophysis species have not been identified. Furthermore, toxin production by $D$. acuminata has been confirmed in laboratory experiments (Hackett et al. 2009, Kamiyama \& Suzuki 2009), indicating a need to examine the effects of environmental factors on toxin production in order to clarify the dynamics of DSP and lipophilic toxins within marine ecosystems.

Temperature may be one of the more important environmental factors influencing population dynamics and cell toxin content of Dinophysis species because growth rates of plankton generally increase with increasing temperature within a certain range. This leads us to assume that the production of cellular DSP and lipophilic toxins by Dinophysis species also depends on environmental temperature.

Our present study was conducted to clarify the effects of temperature on the production of the main toxins causing DSP (okadaic acid [OA] and dinophysistoxin-1 [DTX1]) and a lipophilic toxin (pectenotoxin-2 [PTX2]), as well as on the growth rates of Dinophysis acuminata in culture experiments.

\section{MATERIALS AND METHODS}

Isolation of clonal strains. The marine ciliate Myrionecta rubra and the cryptophyte Teleaulax amphioxeia were isolated from Inokushi Bay, Oita Prefecture, Japan $\left(32^{\circ} 47^{\prime} \mathrm{N}, 131^{\circ} 53^{\prime} \mathrm{E}\right)$ at the end of February 2007 (Nishitani et al. 2008a). The M. rubra culture was maintained by mixing $0.7 \mathrm{ml}$ of the culture (5.0 to $7.0 \times$ $10^{3}$ cells) with $2.3 \mathrm{ml}$ of a modified $\mathrm{f} / 2$ medium and 10 to $15 \mu \mathrm{l}$ of $T$. amphioxeia culture (containing 0.5 to 1.0 $\times 10^{2}$ cells) as food source into each well of 12-well microplates (Iwaki). This culture medium was made up with $1 / 3$ nitrate, phosphate, and metals and $1 / 10$ vitamins of the $f / 2$ medium (Guillard 1975, Nagai et al. 2004) based on the enrichment of Japanese coastal seawater (salinity adjusted to 30 ). A part of the ciliate culture was transferred into fresh culture medium containing the food source once a week, and the culture were maintained at a temperature of $18^{\circ} \mathrm{C}$ under an irradiance of 100 to $150 \mu \mathrm{mol}$ photons $\mathrm{m}^{-2} \mathrm{~s}^{-1}$ provided by cool-white fluorescent lamps with a $12 \mathrm{~h}$ light: $12 \mathrm{~h}$ dark cycle. The $T$. amphioxeia culture was also maintained in the modified f/2 medium in a 24 -well microplate (Iwaki) under the same conditions as M. rubra (Nagai et al. 2008).

Dinophysis acuminata cells were isolated by micropipetting from a seawater sample collected from Inokushi Bay, Oita Prefecture, Japan $\left(32^{\circ} 80^{\prime} \mathrm{N}\right.$, $131^{\circ} 90^{\prime} \mathrm{E}$ ) in November 2007 and established as clonal cultures. The established cultures of $D$. acuminata were maintained in 12-well microplates by repeating inoculation of $300 \mu \mathrm{l}$ of the D. acuminata culture (containing 150 to 250 cells) into $2.7 \mathrm{ml}$ of the Myrionecta rubra culture (containing 3000 to 3500 cells ml ${ }^{-1}$ diluted by one-third with fresh culture medium) once a month under the same conditions as the Teleaulax amphioxeia and M. rubra cultures. All cultures were nonaxenic but were all clonal.

Growth experiment at 4 temperatures. Effect of temperature on toxin production was investigated at 4 temperatures $\left(10,14,18\right.$, and $\left.22^{\circ} \mathrm{C}\right)$ under the same conditions as specified for the maintenance cultures except for temperature. Dinophysis acuminata in northern Japan and northern Europe mostly appear within this temperature range (e.g. Hoshiai et al. 2003, Lindahl et al. 2007). When full consumption of Myrionecta rubra cells by a clonal strain of $D$. acuminata (DA0711INO26) was observed (2 wk after re-inoculation of the culture), the $D$. acuminata cultures in the 12well microplates were placed at each temperature and pre-incubated for $3 \mathrm{wk}$.

After maintenance re-inoculation of the Myrionecta rubra culture, the Dinophysis acuminata cultures were pre-incubated at each temperature for $2 \mathrm{wk}$. Re-inoculation of the cultures (except at $10^{\circ} \mathrm{C}$ ), as described for culture maintenance, took place once after 1 wk preincubation. The M. rubra cultures were grown at each temperature until the late exponential growth (EG) phase (ca. $8.5 \times 10^{3}$ cells ml ${ }^{-1}$ ) and then put together in a plastic vessel. They were diluted with the culture medium to give initial concentrations of ca. 2.3 to $2.4 \times$ $10^{3}$ cells ml ${ }^{-1}$. D. acuminata culture $\left(2000\right.$ cells ml $\mathrm{m}^{-1}$ ) was added to the $M$. rubra cultures to give an initial concentration of ca. 50 cells ml$^{-1}$, and $1.0 \mathrm{ml}$ aliquots of the mixed cultures were pipetted into $>50$ wells of 48 well microplates (Iwaki) for each temperature treat- 
ment. The incubation experiment was conducted for $24 \mathrm{~d}$ at 14,18 and $22^{\circ} \mathrm{C}$ and for $30 \mathrm{~d}$ at $10^{\circ} \mathrm{C}$ under the same light conditions as specified for the maintenance culture. Every $3 d$, cultures in 5 wells were mixed in a tube and used for cell counts $(0.5 \mathrm{ml}$, in triplicate) and for DSP and lipophilic toxin analysis $(1.0 \mathrm{ml}$, in triplicate). Cell densities of $D$. acuminata and $M$. rubra were determined using an inverted microscope. Samples for toxin analysis were kept in a freezer $\left(<-20^{\circ} \mathrm{C}\right)$.

Treatment of plankton samples for toxin analysis. For toxin analysis, we used the solid phase extraction procedure, as described by Kamiyama \& Suzuki (2009; originally reported by Suzuki et al. 1997, 1998). The cell suspensions were thawed, sonicated in an ultrasonic cleaner for $2 \mathrm{~min}$, and loaded onto a Sep-Pak C18 cartridge column (Waters), which had been previously conditioned with $5 \mathrm{ml}$ methanol and $10 \mathrm{ml}$ distilled water. The cartridge was washed with $5 \mathrm{ml}$ distilled water to remove the seawater salt, and the toxins were eluted with $5 \mathrm{ml}$ methanol, which was then evaporated. The residue was dissolved in $200 \mu \mathrm{l}$ methanol and a part of the solution was used for liquid chromatography-tandem mass spectrometry (LC-MS/MS) analysis.

Toxin analysis. LC-MS/MS analysis of toxins was essentially carried out as described by Kamiyama \& Suzuki (2009). A model 1100 liquid chromatograph (Agilent) was coupled to a hybrid triple quadrupole/ linear ion trap mass spectrometer (QTrap 3200; PESCIEX). Separations were performed on Quicksilver cartridge columns $(50 \times 2.1 \mathrm{~mm}$ internal diameter $)$ packed with $3 \mathrm{~mm}$ Hypersil-BDS-C8 (Keystone Scientific) and maintained at $20^{\circ} \mathrm{C}$. Eluent $\mathrm{A}$ was water and eluent B was acetonitrile-water (95:5, vol:vol), both containing $2 \mathrm{mM}$ ammonium formate and $50 \mathrm{mM}$ formic acid. Toxins were eluted from the column with

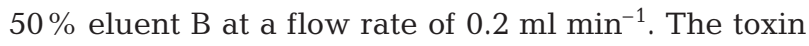
concentration of the sample was determined by comparing the peak areas of each toxin with those of the standard toxins for OA, DTX1, and PTX2, which were provided by Japan Food Research Laboratories (Tokyo, Japan). The lowest detection limits for OA, DTX1 and PTX2 were 0.6, 0.6 and $1.6 \mathrm{ng} \mathrm{ml}^{-1}$, respectively. These levels are equivalent to $1.2 \mathrm{pg} \mathrm{cell}^{-1}$ of OA/DTX1 and 3.2 pg cell $^{-1}$ of PTX2, when 100 cells of the toxic plankton were analyzed using our LCMS/MS method.

Data analysis. Specific growth rates $\left(\mu_{i} \mathrm{~d}^{-1}\right)$ of Dinophysis acuminata between sampling intervals $(t ; 3 \mathrm{~d})$ was calculated from the EG equation:

$$
\mu=\frac{\ln \left(N_{2} / N_{1}\right)}{t}
$$

where $N_{1}$ and $N_{2}$ are the cell densities of D. acuminata at the first and subsequent sampling, respectively. The mean specific growth rates of $D$. acuminata were determined from the slope of the linear regression of the natural logarithm of cell density versus incubation time during the EG period.

Cellular content of OA, DTX1, and PTX2 of Dinophysis acuminata was determined by dividing the toxin concentration by the cell density at each time point of incubation. Effects of temperature on cellular toxin content and toxin production rates of Dinophysis acuminata were examined by 1-way ANOVA, or by the Kruskal-Wallis test if the variance of data at each temperature was not homogeneous, and the differences in these values and growth rates between 2 temperatures were examined by the Student's $t$-test. The trends of cellular toxin content and production rate during the incubation period were examined by Spearman's rank correlation coefficient (Spearman's RCC).

\section{RESULTS}

\section{Growth at different temperatures}

Cell density of Dinophysis acuminata increased at all temperatures from the initiation of incubation and reached maximum values of $1.69 \times 10^{3}$ to $4.17 \times 10^{3}$ cells $\mathrm{ml}^{-1}$ (Fig. 1). Analysis of the growth curves showed the EG phase to be shorter at higher temperatures: $24 \mathrm{~d}$ at $10^{\circ} \mathrm{C}, 18 \mathrm{~d}$ at 14 and $18^{\circ} \mathrm{C}$, and $15 \mathrm{~d}$ at $22^{\circ} \mathrm{C}$. In contrast, cell density of Myrionecta rubra exponentially decreased after $6 \mathrm{~d}$ of incubation, with this decrease occurring more rapidly at higher temperatures (Fig. 1), and cells disappeared after $9 \mathrm{~d}$ of incubation at $22^{\circ} \mathrm{C}, 12 \mathrm{~d}$ at $18^{\circ} \mathrm{C}, 18 \mathrm{~d}$ at $14^{\circ} \mathrm{C}$, and $27 \mathrm{~d}$ at $10^{\circ} \mathrm{C}$. The mean specific growth rates of $D$. acuminata during the EG phase ranged from 0.14 to $0.28 \mathrm{~d}^{-1}$ (equivalent to 0.20 to 0.40 divisions $\mathrm{d}^{-1}$ ) and was greater at higher temperatures (Table 1). The differences in the growth rates between $10^{\circ} \mathrm{C}$ and higher temperatures and between $14^{\circ} \mathrm{C}$ and $22^{\circ} \mathrm{C}$ were significant (Student's $t$-test, $\mathrm{p}<0.05$ ). The maximum specific growth rates per $3 \mathrm{~d}$ sampling interval ranged from 0.29 to $0.50 \mathrm{~d}^{-1}$ (0.41 to 0.73 divisions $\mathrm{d}^{-1}$; Table 1 ).

\section{Toxin production at different temperatures}

Toxin concentrations in Dinophysis acuminata cultures increased exponentially during the EG phase (Fig. 2). Toxin yields reached a maximum of 16.0 to $120.2 \mathrm{ng} \mathrm{ml}^{-1}$ for OA, 1.2 to $3.9 \mathrm{ng} \mathrm{ml}^{-1}$ for DTX1, and 203.9 to $447.3 \mathrm{ng} \mathrm{ml}^{-1}$ for PTX2 and were greater at higher temperatures for all toxins.

During the EG phase, the cellular toxin content increased significantly with increasing incubation 

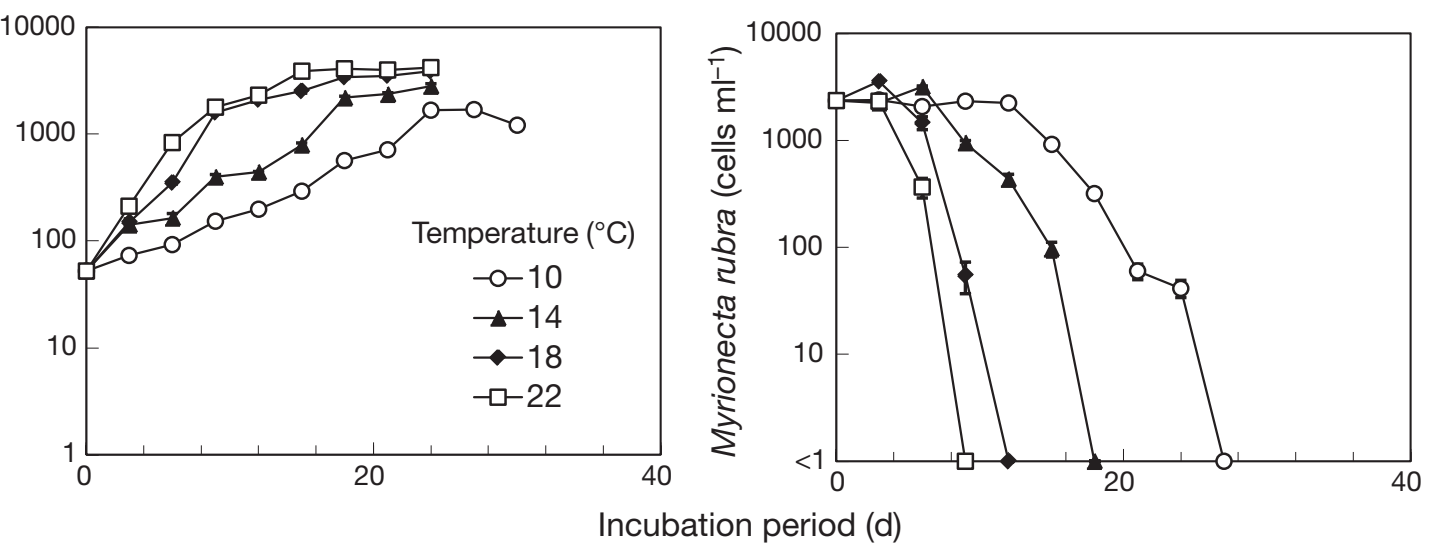

Fig. 1. Dinophysis acuminata and Myrionecta rubra. Growth of D. acuminata and M. rubra. Cell densities at 4 different temperatures. Vertical bars denote SE of the mean $(n=3)$

periods at temperatures of 14,18 , and $22^{\circ} \mathrm{C}$ for $\mathrm{OA}$ and at all temperatures for DTX1 (Spearman's RCC, p < 0.05) (Fig. 3). If the cellular contents of all components after the EG phase are excluded, as mentioned in the Discussion, the cellular toxin contents reached a maximum of 11.9 to $16.8 \mathrm{pg} \mathrm{cell}^{-1}$ at 14,18 , and $22^{\circ} \mathrm{C}$ for OA and 0.5 to $0.7 \mathrm{pg} \mathrm{cell}^{-1}$ at all temperatures for DTX1, which is 2.8 to 5.1 and 2.5 to 4.2 times higher than initial values, respectively. This relationship with the incubation period was not observed at $10^{\circ} \mathrm{C}$ for OA. Mean cellular toxin content at each temperature during the EG period was 8.06 to $8.66 \mathrm{pg} \mathrm{cell}^{-1}$ for OA and 0.24 to $0.34 \mathrm{pg} \mathrm{cell}^{-1}$ for DTX1 (Table 2). Differences among temperatures were not significant for either OA or DTX1 (Kruskal-Wallis test, $H=0.69, \mathrm{p}>0.05$ for OA; 1 -way ANOVA, $F=0.56, \mathrm{p}>0.05$ for DTX1). For PTX2, cellular content of the toxin as a function of incubation period did not show a significant trend at 14 to $22^{\circ} \mathrm{C}$ (Spearman's RCC, p > 0.05), whereas at $10^{\circ} \mathrm{C}$, the value significantly increased with incubation period. Mean cellular toxin content at each temperature during the EG period ranged from 57.10 to $107.05 \mathrm{pg} \mathrm{cell}^{-1}$ and was significantly greater at lower temperatures (1-way ANOVA, $F=8.49, \mathrm{p}<0.01$ ).

Table 1. Dinophysis acuminata. Maximum and mean (SE) growth rates during the exponential growth (EG) phase at 4 temperatures in culture experiments

\begin{tabular}{|c|c|c|c|c|c|}
\hline \multirow{2}{*}{$\begin{array}{l}\text { Temp. } \\
\left({ }^{\circ} \mathrm{C}\right)\end{array}$} & \multirow{2}{*}{$\begin{array}{l}\text { Duration of } \\
\text { EG phase }(d)\end{array}$} & \multicolumn{3}{|c|}{ Specific growth rate $\left(\mu, \mathrm{d}^{-1}\right)$} & \multirow[t]{2}{*}{$\mathrm{n}$} \\
\hline & & Maximum & Mean & $(\mathrm{SE})$ & \\
\hline 10 & 24 & 0.29 & 0.14 & $(0.01)$ & 9 \\
\hline 14 & 18 & 0.34 & 0.19 & $(0.02)$ & 7 \\
\hline 18 & 18 & 0.50 & 0.24 & $(0.03)$ & 7 \\
\hline 22 & 15 & 0.47 & 0.28 & $(0.04)$ & 6 \\
\hline
\end{tabular}
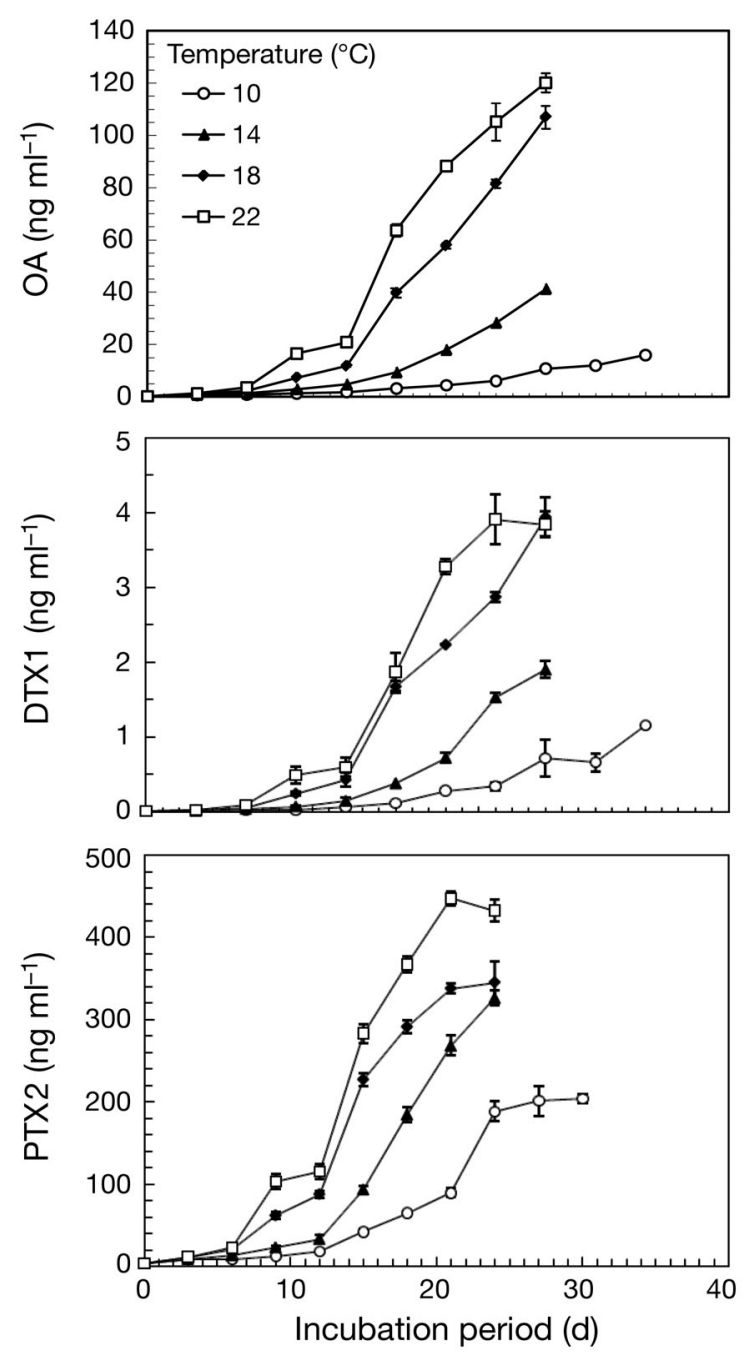

Fig. 2. Dinophysis acuminata. Changes in concentrations of okadaic acid (OA), dinophysistoxin-1 (DTX1), and pectenotoxin-2 (PTX2) in cultures at 4 different temperatures. Vertical bars denote SE of the mean $(n=3)$ 

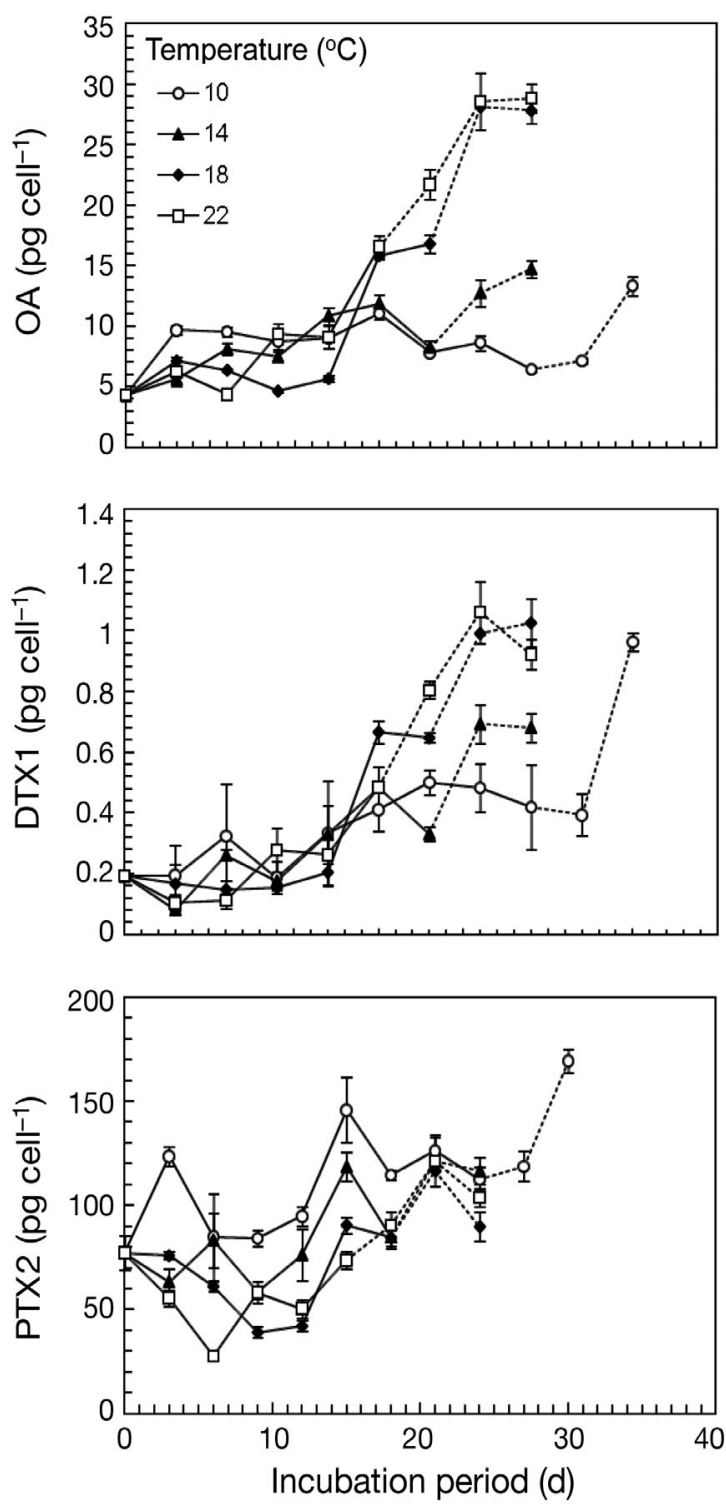

Fig. 3. Dinophysis acuminata. Changes in cellular content of okadaic acid (OA), dinophysistoxin-1 (DTX1), and pectenotoxin-2 (PTX2) at 4 different temperatures. Data on dashed lines denote the values during the stationary growth phase.

Vertical bars denote SE of the mean $(n=3)$

\section{DISCUSSION}

\section{Effects of temperature on growth rates}

In the present study the mean specific growth rates of Dinophysis acuminata at temperatures from 10 to $22^{\circ} \mathrm{C}$ ranged from 0.14 to $0.28 \mathrm{~d}^{-1}$ (maximum 0.29 to $0.50 \mathrm{~d}^{-1}$ ) during the EG period. In situ growth rates of $D$. acuminata have previously been reported as ranging from 0.09 to $0.67 \mathrm{~d}^{-1}$ (Table 1 in Nagai et al. 2008), and maximum values based on previous culture experiments range from 0.45 to $0.95 \mathrm{~d}^{-1}$ at $20^{\circ} \mathrm{C}$ (Park et al. 2006, Kim et al. 2008, Riisgaard \& Hansen 2009) and $0.67 \mathrm{~d}^{-1}$ at $15^{\circ} \mathrm{C}$ (Kamiyama \& Suzuki 2009). Compared to values from previous culture experiments, the maximum growth rates of $D$. acuminata in the present study are somewhat low. The growth rates could be influenced by other experimental conditions, such as quality of prey organisms, experimental scale, and genetic characteristics of $D$. acuminata.

Temperature is an important factor influencing growth of plankton. The specific growth rate $(\mu)$ of protists is expected to increase exponentially with increases in temperature (e.g. Eppley 1972), and the $Q_{10}$ model is often used to fit the relationships (e.g. Hansen et al. 1997). However, Montagnes et al. (2003) proposed that the growth rate of aquatic protists usually responds linearly to temperature. Hence, the relationship between the growth rate of Dinophysis acuminata and temperature in this study was fitted to a linear regression, with the slope of the regression line calculated to be $0.012 \mathrm{~d}^{-1}{ }^{\circ} \mathrm{C}^{-1}\left(\mathrm{n}=4, \mathrm{SE}=0.000, \mathrm{r}^{2}=0.999\right)$. This is lower than the values reported for other dinoflagellates (0.014 to $0.077 \mathrm{~d}^{-1}{ }^{\circ} \mathrm{C}^{-1}$ ) (Montagnes et al. 2003), suggesting that the growth rates of $D$. acuminata are not as sensitive to temperature as those of other heterotrophic and autotrophic dinoflagellates. Alternatively the relationship of temperature to growth rates of D. acuminata presented here could have been influenced by factors contributing to the lower observed growth rates.

Dinophysis acuminata is a cosmopolitan species that is distributed in coastal waters worldwide and is a

Table 2. Dinophysis acuminata. Cellular toxin contents during the exponential growth (EG) phase at 4 temperatures in culture experiments

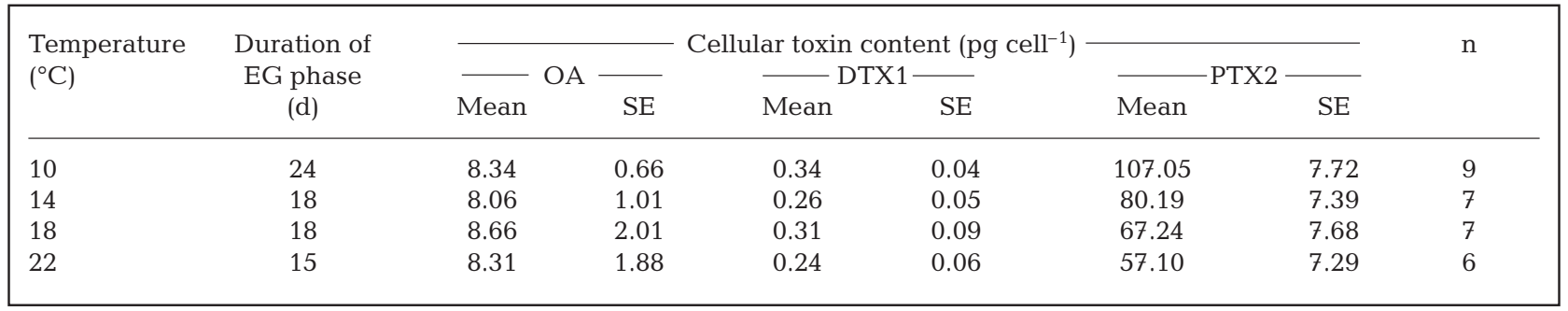


causative species of DSP and lipophilic toxin contamination of bivalves in New Zealand, Chile, Japan, and along the Atlantic coasts of Europe (van Egmond et al. 1993, Reguera \& Pizarro 2009). In coastal waters of the western Pacific Ocean, D. acuminata appears abundantly in embayments in contrast to the other Dinophysis species, D. fortii (Hoshiai et al. 2003). The variations in distribution and seasonal occurrence reported in previous studies (Hoshiai et al. 2003, Miyazono et al. 2008) can be explained by the ability of $D$. acuminata to grow over a wide temperature range, as demonstrated in the present study.

\section{Toxin contents and production}

The results from the present study show that cultured Dinophysis acuminata actively produces OA and PTX2, supporting the findings of Kamiyama \& Suzuki (2009) and Hackett et al. (2009). In Japan, accumulated data based on extensive monitoring of shellfish toxin using mouse bioassays indicate that DSP events (here, contamination of shellfish toxin due to okadaic acid analogues and other lipophilic toxins) exceeding a quarantine level have only infrequently occurred in northern and western regions (Yamamoto and Yamasaki 1996), although Dinophysis species commonly appear in coastal waters of western as well as northern Japan (Imai et al. 2006). The strain of D. acuminata used in the present study was isolated from seawater off western Japan. High concentrations of PTX2 and detection of OA and DTX1 at all temperatures suggest a risk of DSP despite having never been reported.

Although some toxins of Dinophysis spp. are released into surrounding seawater (MacKenzie et al. 2004), we assumed that the 3 toxins measured in the present study were components of the $D$. acuminata cells during the EG phase because of the results of a previous study (Kamiyama \& Suzuki 2009). In our previous culture experiments, we did not detect toxins (PTX2 and DTX1) released into seawater from $D$. acuminata cells at the late EG phase or early stationary growth phase. However, $4 \mathrm{~d}$ after these phases, the released toxins accounted for $13 \%(\mathrm{PTX} 2, \mathrm{n}=4)$ and $24 \%$ (DTX1, n = 4) of total toxin content, on average, in the suspension (Kamiyama \& Suzuki 2009, raw data not shown). This suggests that the amount of toxin released into seawater from cells relative to the total toxin concentration rapidly increases with incubation period during the stationary growth phase, even if it is negligible in the initial phase of cultivation. In our present study, cellular toxin content calculated by dividing toxin concentration by cell density often increased rapidly after the EG phase. However, overestimation of the cellular toxin content during the stationary growth phase due to an increase in dissolved toxin fractions cannot be ruled out.

Cellular toxin content in natural Dinophysis acuminata cells ranges from 0 to $40 \mathrm{pg} \mathrm{cell}^{-1}$ for OA in coastal waters of Europe, Japan, Canada, and Sweden, 3 to $50 \mathrm{pg} \mathrm{cell}{ }^{-1}$ for OA in the Bay of Seine (France), and from 0 to $0.02 \mathrm{pg} \mathrm{cell}^{-1}$ and 0.1 to $2.4 \mathrm{pg} \mathrm{cell}^{-1}$ for DTX1 in coastal waters of Sweden and New Zealand, respectively (Marcaillou et al. 2001, MacKenzie et al. 2005, summary in Lindahl et al. 2007). Recent work using LC-MS/MS analysis also indicates that PTX2 is a dominant toxin of $D$. acuminata around the coast of the South Island of New Zealand (cellular toxin content 2.4 to $25.8 \mathrm{pg} \mathrm{cell}{ }^{-1}$; MacKenzie et al. 2005) and off Hokkaido, northern Japan (cellular toxin content 0 to 50.2 pg cell $^{-1}$; Miyazono et al. 2008, Suzuki et al. 2009). Kamiyama \& Suzuki (2009) showed that the cellular toxin content of cultured D. acuminata was 4.8 to $14.7 \mathrm{pg} \mathrm{cell}{ }^{-1}$ for PTX2 and 2.5 to $4.8 \mathrm{pg} \mathrm{cell}^{-1}$ for DTX1. PTX2 levels (57 to 107 pg cell $^{-1}$ ) of D. acuminata in the present study were considerably higher than those from previous field samples and culture samples reported by Kamiyama \& Suzuki (2009). In contrast, DTX1 (0.24 to $0.34 \mathrm{pg} \mathrm{cell}^{-1}$ ) and OA (8.06 to $8.65 \mathrm{pg}$ $\mathrm{cell}^{-1}$ ) levels in the present study were within the range of previous data, although the DTX1 values were low compared to the data of Kamiyama \& Suzuki (2009).

The toxin content of toxic dinoflagellates reflects the initial amount of toxin in a cell and gross toxin production. The gross production reflects the balance between net toxin synthesis and toxin losses due to catabolism and leakage or cell division (toxin partly transferred to new daughter cells) (Anderson et al. 1990). The loss of toxin due to cell division is probably important in culture experiments. Hence, to clarify the dynamics of toxin production, cellular toxin production rates $\left(\mathrm{CTP}_{\text {; }}\right.$ g cell $\left.{ }^{-1} \mathrm{~d}^{-1}\right)$ were determined from the following equation for each time point:

$$
\mathrm{CTP}=\frac{\left(T_{2}-T_{1}\right)}{N_{\mathrm{m}} \times t}, \quad N_{m}=\frac{\left(N_{2}-N_{1}\right)}{\ln \left(N_{2} / N_{1}\right)}
$$

where $N_{1}$ and $N_{2}$ are the cell densities of $D$. acuminata and $T_{1}$ and $T_{2}$ are the toxin concentrations, both parameters at the first and the subsequent sampling times, respectively, and $N_{\mathrm{m}}$ is the geometric mean density of $D$. acuminata during the sampling period.

As a result, the mean cellular toxin production rates for the entire incubation period were 1.18 to $2.31 \mathrm{pg}$ cell ${ }^{-1} \mathrm{~d}^{-1}$ for OA, 0.06 to $0.08 \mathrm{pg}_{\text {cell }}^{-1} \mathrm{~d}^{-1}$ for DTX1, and 10.7 to $15.6 \mathrm{pg} \mathrm{cell}{ }^{-1} \mathrm{~d}^{-1}$ for PTX2. The CTP are available after the EG phase as well because the toxins released into the surrounding waters were also produced by Dinophysis acuminata cells. The mean cellular production rate of OA increased with increasing temperature (Kruskal-Wallis test, $H=8.39, \mathrm{p}<0.05$ ). 
The mean cellular production rate of DTX1 was fairly similar at all temperatures (1-way ANOVA, $F=0.16$, $\mathrm{p}>0.05$ ) and that of PTX2 did not significantly differ between temperatures (1-way ANOVA, $F=0.42, \mathrm{p}>$ 0.05). The cellular production rates of PTX2 decreased with increasing incubation time at $18^{\circ} \mathrm{C}$ and $22^{\circ} \mathrm{C}$ (Spearman's RCC, p < 0.05). The temporary peaks of the cellular toxin production rates occurred at or just before the end of the EG phase, except for OA and DTX1 at $10^{\circ} \mathrm{C}$ (Fig. 4). This can be explained by the temporary decrease in the loss of toxin from cell division when the growth mode of $D$. acuminata shifts from the active to inactive state. Anderson et al. (1990) found that specific toxin production rates of Alexandrium spp. mostly corresponded to between 2 and 0.5 times the specific growth rates. The results of our study also indicate a significant linear correlation between toxin production rates and specific growth rates in $D$. acuminata for all 3 toxins (Fig. 5). However, 44 to $53 \%$ of the specific toxin production rates were outside the range denoted by 2 and 0.5 times the specific growth rates. This suggests that toxin production rates in $D$. acuminata may vary in response to factors other than growth rate.

Previous studies have reported that the content and composition of paralytic shellfish poisoning toxins of Alexandrium spp. are strongly influenced by temperature (Etheridge \& Roesler 2005, Navarro et al. 2006). Based on those studies and the results from our present study, we expected that temperature would be an

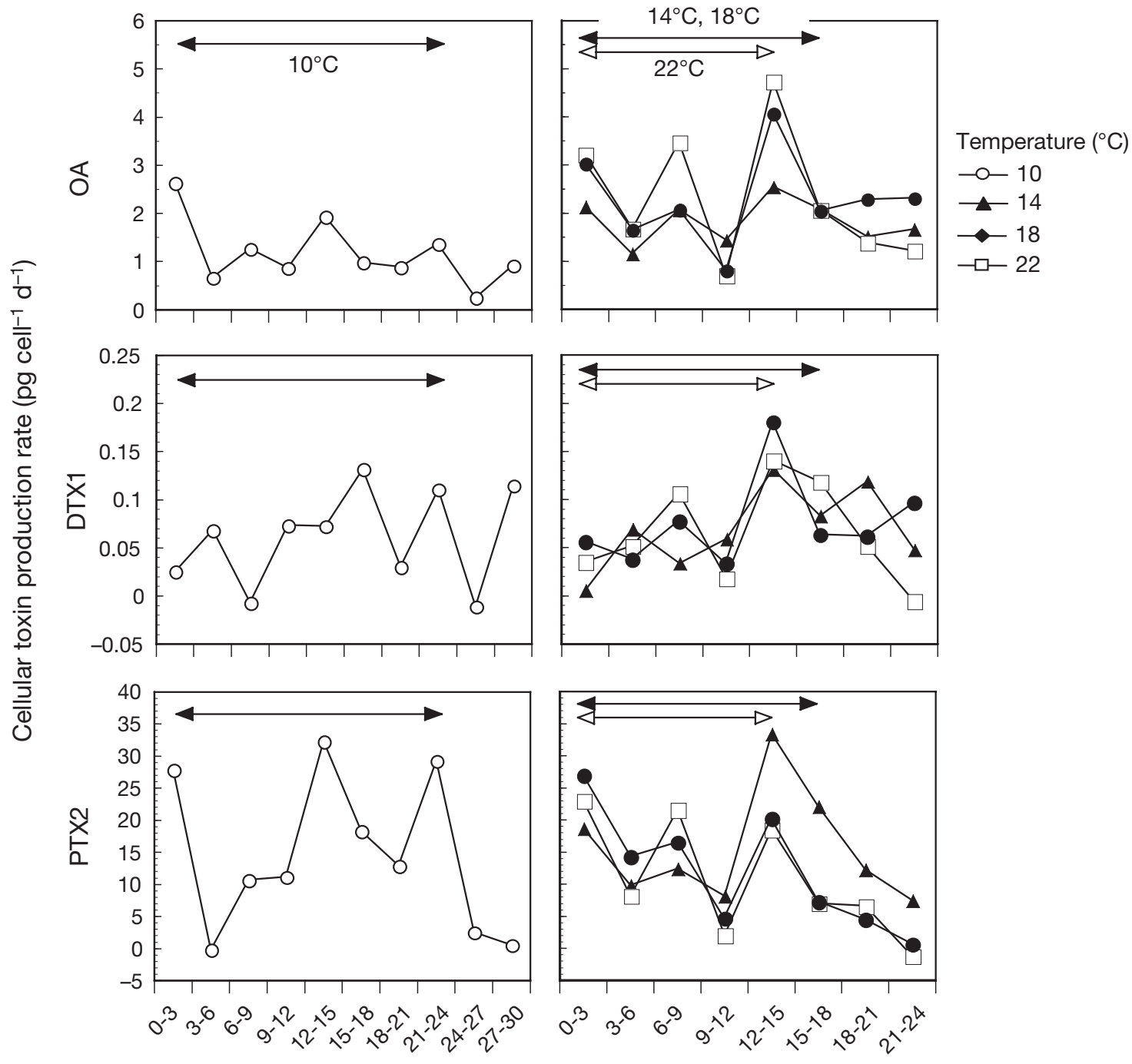

Incubation period (d)

Fig. 4. Dinophysis acuminata. Changes in cellular toxin production rate (CTP) of okadaic acid (OA), dinophysistoxin-1 (DTX1), and pectenotoxin-2 (PTX2) at 4 different temperatures. Arrows indicate the period of exponential growth at $10^{\circ} \mathrm{C}$ (left column) and at the other temperatures (right column) 


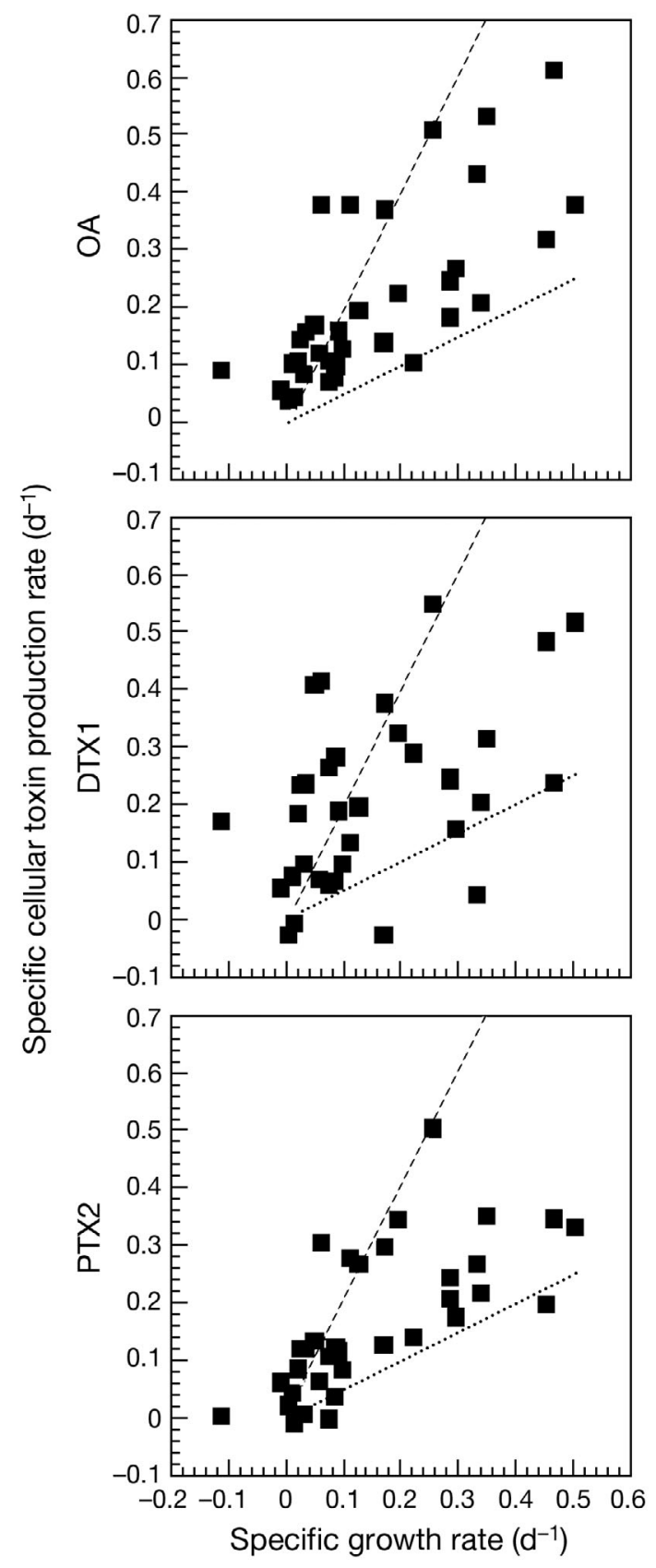

Fig. 5. Dinophysis acuminata. Relationship between specific toxin production rate and specific growth rate during each $3 \mathrm{~h}$ sampling interval at all temperatures. Dashed and dotted lines denote toxin production rates $2 \times$ and $0.5 \times$ that of specific growth rates, respectively

important factor in the production of the 3 toxins by Dinophysis acuminata. Interestingly, OA/DTX1 and PTX2 production clearly differed in response to temperature. The mean cellular content of OA and DTX1 during the EG phase was independent of the temperature, although cellular content of the toxins increased with increasing incubation time during the EG phase at higher temperatures. This suggests that temperature does not directly influence toxin production but that population growth in response to temperature influences cellular content and production of OA and DTX1. In particular, a rapid increase in cellular OA and DTX1 occurred after consumption of Myrionecta rubra, suggesting an association with plastids originating from prey and their function, as discussed below. On the other hand, the mean cellular content of PTX2 during the EG phase was higher at lower temperatures, and during the first $21 \mathrm{~d}$, was higher at $10^{\circ} \mathrm{C}$ than at other temperatures (Fig. 3). A significant variation in response to incubation period only occurred at $10^{\circ} \mathrm{C}$. These results suggest that temperature may directly influence cellular production of PTX2. The different responses of OA/DTX1 and PTX2 production to temperature may be caused by a difference in the toxin production mechanism.

Uptake of prey (Myrionecta rubra) is not only important for growth (Park et al. 2006, Kim et al. 2008, Riisgaard \& Hansen 2009) but may also be an important factor in the variations observed in cellular toxin content and production during incubation. Uptake of $M$. rubra by Dinophysis acuminata influences dinoflagellate photosynthetic activity (Riisgaard \& Hansen 2009). Toxin synthesis by the DSP toxin producer Prorocentrum lima is considered to be a light-mediated metabolic process (Pan et al. 1999), implying that photosynthesis influences cellular toxin production by toxic phytoplankton. Dinophysis spp. depend on plastids from prey for photosynthesis (kleptoplastidy) (Park et al. 2006, Nagai et al. 2008). Hence, uptake of plastids from the food source through the feeding process possibly induced the variations in cellular toxin production that we observed. Also, the heterotrophic energy source obtained by feeding on $M$. rubra may be directly associated with toxin production. A more rapid increase in toxin concentration with incubation periods at higher temperature corresponded to a more rapid decrease in $M$. rubra due to active feeding. However, an experiment to estimate feeding rates of $D$. acuminata on $M$. rubra was not conducted in this study. Further studies are needed to clarify the effects of feeding on prey organisms on toxin production and the complex relationship between photosynthesis and toxin production.

Toxin concentration increased with increasing Dinophysis acuminata cell density at all temperatures, showing that $D$. acuminata growth rate is clearly an important factor promoting the production of toxins. Additionally, the combined effects of temperature and growth phase on cellular toxin content and production rates may explain the large variation in cellular toxin content of Dinophysis spp. in seawater. Since D. acuminata occurs in a wide range of temperature condi- 
tions, the cellular content of PTX2 and OA in the D. acuminata population possibly varies seasonally, with PTX2 increasing during cooler seasons and OA increasing during warmer seasons when $D$. acuminata is actively growing. However, in the present situation, we cannot further discuss the differences in cellular toxin contents reported in previous studies on the basis of the effects of temperature on the cellular toxin contents observed in the present study, because the range of cellular toxin contents of field $D$. acuminata is very broad even if samples are collected in the same season (Andersen et al. 1996). Cell toxicity in field D. acuminata is probably influenced not only by temperature but also by other factors such as genetic characteristics. Further studies are necessary to document temperature-dependent variations in toxicity for each Dinophysis species in natural seawaters.

\section{CONCLUSIONS}

This is the first culture experiment addressing the effect of temperature on the growth and toxicity of Dinophysis acuminata. Our results showed that temperature affects growth rates and toxin production of $D$. acuminata and that cell toxicity varies during the EG phase. These findings partly suggest that there is a wide variation in cell toxicity in natural populations of D. acuminata. However, toxin production by Dinophysis spp. may depend on genetic characteristics or the fact that populations from different strains may show different growth responses to temperature. Further investigations are needed on the toxicity of various strains of Dinophysis spp. isolated from seawater from different areas having a range of environmental conditions.

Acknowledgements. This work was supported by a Grant-InAid for Scientific Research (Kiban-B) from the Japan Society for the Promotion of Science (No. 20380116). We thank the Japan Food Research Laboratories for providing OA, DTX1, and PTX2 standards.

\section{LITERATURE CITED}

Andersen P, Benedicte H, Emsholm H (1996) Toxicity of Dinophysis acuminata in Danish coastal waters. In: Yasumoto T, Oshima Y, Fukuyo Y (eds) Harmful and toxic algal blooms. Intergovernmental Oceanographic Commission of UNESCO, Paris, p 281-284

Anderson DM, Kulis DM, Sullivan JJ, Hall S, Lee C (1990) Dynamics and physiology of saxitoxin production by the dinoflagellates Alexandrium spp. Mar Biol 104:511-524

Cruz PG, Daranas AH, Fernández JJ, Souto ML, Norte M (2006) DTX5c, a new OA sulphate ester derivative from cultures of Prorocentrum belizeanum. Toxicon 47:920-924

Della Loggia R, Cabrini M, Del Negro P, Honsell G, Tubaro A (1993) Relationships between Dinophysis spp. in seawater and DSP toxins in mussels in the Northern Adriatic Sea. In: Smayda TJ, Shimizu Y (eds) Toxic phytoplankton blooms in the sea. Elsevier, Amsterdam, p 483-488

Eppley RW (1972) Temperature and phytoplankton growth in the sea. Fish Bull 70:1063-1085

Etheridge SM, Roesler CS (2005) Effects of temperature, irradiance, and salinity on photosynthesis, growth rates, total toxicity, and toxin composition for Alexandrium fundyense isolates from the Gulf of Maine and Bay of Fundy. DeepSea Res II 52:2491-2500

> Foden J, Purdie DA, Morris S, Nascimento S (2005) Epiphytic abundance and toxicity of Prorocentrum lima populations in the Fleet Lagoon, UK. Harmful Algae 4:1063-1074

Guillard RRL (1975) Culture of phytoplankton for feeding marine invertebrates. In: Smith WL, Chanley MH (eds) Culture of marine invertebrate animals. Plenum Press, New York, NY, p 26-60

> Hackett JD, Tong M, Kulis DM, Fux E, Hess P, Bire R, Anderson DM (2009) DSP toxin production de novo in cultures of Dinophysis acuminata (Dinophyceae) from North America. Harmful Algae 8:873-879

Hallegraeff GM (1993) A review of harmful algal blooms and their apparent global increase. Phycologia 32:79-99

Hallegraeff GM, Lucas IAN (1988) The marine dinoflagellate genus Dinophysis (Dinophyceae): photosynthetic, neritic and non-photosynthetic, oceanic species. Phycologia 27: $25-42$

Hansen PJ, Bjørnsen PK, Hansen BW (1997) Zooplankton grazing and growth: scaling within the 2-2000- $\mu \mathrm{m}$ body size range. Limnol Oceanogr 42:687-704

Hoshiai G, Suzuki T, Onodera T, Yamasaki M, Taguchi S (1997) A case of non-toxic mussels under the presence of high concentrations of toxic dinoflagellate Dinophysis acuminata that occurred in Kesennuma Bay, Northern Japan. Fish Sci 63:317-318

> Hoshiai G, Suzuki T, Kamiyama T, Yamasaki M, Ichimi K (2003) Water temperature and salinity during the occurrence of Dinophysis fortii and D. acuminata in Kesennuma Bay, northern Japan. Fish Sci 69:1303-1305

Imai I, Yamaguchi M, Hori Y (2006) Eutrophication and occurrences of harmful algal blooms in the Seto Inalnd Sea, Japan. Plankton Benthos Res 1:71-84

Kamiyama T, Suzuki T (2009) Production of dinophysistoxin-1 and pectenotoxin-2 by a culture of Dinophysis acuminata (Dinophyceae). Harmful Algae 8:312-317

Kim S, Kang YG, Kim HS, Yih W, Coats DW, Park MG (2008) Growth and grazing responses of the mixotrophic dinoflagellate Dinophysis acuminata as functions of light intensity and prey concentration. Aquat Microb Ecol 51: 301-310

Koike $\mathrm{K}$, Otobe $\mathrm{H}$, Takagi M, Yoshida T, Ogata T, Ishimaru T (2001) Recent occurrences of Dinophysis fortii (Dinophyceae) in the Okkirai Bay, Sanriku, Northern Japan, and related environmental factors. J Oceanogr 57: $165-175$

Lindahl O, Lundve B, Johansen M (2007) Toxicity of Dinophysis spp. in relation to population density and environmental conditions on the Swedish west coast. Harmful Algae 6:218-231

MacKenzie L, Beuzenberg V, Holland P, McNabb P, Selwood A (2004) Solid phase adsorption toxin tracking (SPATT): a new monitoring tool that simulates the biotoxin contamination of filter feeding bivalves. Toxicon 44:901-918

> MacKenzie L, Beuzenberg V, Holland P, McNabba P, Suzuki T, Selwood A (2005) Pectenotoxin and okadaic acid-based toxin profiles in Dinophysis acuta and Dinophysis acuminata from New Zealand. Harmful Algae 4:75-85 
Maranda L, Corwin S, Dover S, Morton SL (2007a) Prorocentrum lima (Dinophyceae) in northeastern USA coastal waters. II Toxin load in the epibiota and in shellfish. Harmful Algae 6:632-641

Maranda L, Corwin S, Hargraves PE (2007b) Prorocentrum lima (Dinophyceae) in northeastern USA coastal waters. I. Abundance and distribution. Harmful Algae 6:623-631

Marcaillou C, Gentien P, Lunven M, Le Grand J and others (2001) Dinophysis acuminata distribution and specific toxin content in relation to mussel contamination. In: Hallegraeff GM, Blackburn SI, Bolch CJ, Lewis RJ (eds). Harmful algal blooms 2000. Intergovernmental Oceanographic Commission of UNESCO, Paris, p 356-59

Miyazono A, Suzuki T, Baba K, Sugawara R (2008) Occurrence of Dinophysis spp. and temporal changes in diarrhetic shellfish poison and lipophilic toxins in Dinophysis spp. in Funka Bay, Hokkaido. Bull Plankton Soc Japan 55:25-28 (Japanese with English abstract)

Montagnes DJS, Kimmance SA, Atkinson D (2003) Using $Q_{10}$ : Can growth rates increase linearly with temperature? Aquat Microb Ecol 32:307-313

Nagai S, Matsuyama Y, Oh SJ, Itakura S (2004) Effect of nutrients and temperature on encystment of the toxic dinoflagellate Alexandrium tamarense (Dinophyceae) isolated from Hiroshima Bay, Japan. Plankton Biol Ecol 51: 103-109

Nagai S, Nitshitani G, Tomaru Y, Sakiyama S, Kamiyama T (2008) Predation by the toxic dinoflagellate Dinophysis fortii on the ciliate Myrionecta rubra and observation of sequestration of ciliate chloroplasts. J Phycol 44:909-922

Navarro JM, Munoz MG, Contreras AM (2006) Temperature as a factor regulating growth and toxin content in the dinoflagellate Alexandrium catenella. Harmful Algae 5: 762-769

Nishitani G, Sugioka H, Imai I (2002) Seasonal distribution of species of the toxic dinoflagellate genus Dinophysis in Maizuru Bay (Japan) with comments on their autofluorescence and attachment of picophytoplankton. Harmful Algae 1:253-264

Nishitani G, Yamaguchi M, Ishikawa A, Yanagiya S, Mitsuya T, Imai I (2005) Relationships between occurrences of toxic Dinophysis species (Dinophyceae) and small phytoplanktons in Japanese coastal waters. Harmful Algae 4:755-762

Nishitani G, Nagai S, Sakiyama S, Kamiyama T (2008a) Successful cultivation of the toxic dinoflagellate Dinophysis caudata (Dinophyceae). Plankton Benthos Res 3:78-85

Nishitani G, Nagai S, Takano Y, Sakiyama S, Baba K, Kamiyama T (2008b) Growth characteristics and phylogenetic analysis of the marine dinoflagellate Dinophysis infundibulus (Dinophyceae). Aquat Microb Ecol 52: 209-221

Pan Y, Cembella AD, Quilliam MA (1999) Cell cycle and toxin production in the benthic dinofagellate Prorocentrum lima. Mar Biol 134:541-549

Editorial responsibility: Patricia Glibert, Cambridge, Maryland, USA
Park MG, Kim S, Kim HS, Myung G, Kang YG, Yih W (2006) First successful culture of the marine dinoflagellate Dinophysis acuminata. Aquat Microb Ecol 45:101-106

Quilliam MA, Gilgan MW, Pleasance S, Defreitas ASW and others (1993) Confirmation of an incident of diarrhetic shellfish poisoning in Eastern Canada. In: Smayda TJ, Shimizu Y (eds) Toxic phytoplankton blooms in the sea: Proc 5th Int Conf Toxic Marine Phytoplankton, Newport, RI, USA. Elsevier Science Publication, New York, NY, p 547-552

Reguera B, Pizarro G (2009) Planktonic dinoflagellates that contain polyether toxins of the old 'DSP Complex'. In: Botana LM (ed) Seafood and freshwater toxins: pharmacology, physiology, and detection, 2nd edn. CRC press, Boca Raton, FL, p 257-284

> Riisgaard K, Hansen PJ (2009) Role of food uptake for photosynthesis, growth and survival of the mixotrophic dinoflagellate Dinophysis acuminata. Mar Ecol Prog Ser 381: $51-62$

Suzuki T, Mitsuya T, Imai M, Yamasaki M (1997) DSP toxin contents in Dinophysis fortii and scallops collected at Mutsu Bay, Japan. J Appl Phycol 8:509-515

Suzuki T, Mitsuya T, Matsubara H, Yamasaki M (1998) Determination of pectenotoxin-2 after solid-phase extraction from seawater and from the dinoflagellate Dinophysis fortii by liquid chromatography with electrospray mass spectrometry and ultraviolet detection: evidence of oxidation of pectenotoxin- 2 to pectenotoxin- 6 in scallops. J Chromatogr A 815:155-160

Suzuki T, Miyazono A, Baba K, Sugawara R, Kamiyama T (2009) LC-MS/MS analysis of okadaic acid analogues and other lipophilic toxins in single-cell isolates of several Dinophysis species collected in Hokkaido, Japan. Harmful Algae 8:233-238

Ten-Hage L, Delaunay N, Pichon V, Couté A, Puiseux-Dao S, Turquet J (2000) Okadaic acid production from the marine benthic dinoflagellate Prorocentrum arenarium Faust (Dinophyceae) isolated from Europa Island coral reef ecosystem (SW Indian Ocean). Toxicon 38:1043-1054

van Egmond HP, Anne T, Lassus P, Speijers GJA, Waldock M (1993) Paralytic and diarrhoeic shellfish poisons: occurrence in Europe, toxicity, analysis and regulation. J Nat Toxins 2:41-64

Yamamoto M, Yamasaki M (1996) Japanese monitoring system on shellfish toxins. In: Yasumoto $T$, Oshima $Y$, Fukuyo Y (eds) Harmful and toxic algal blooms. Intergovernmental Oceanographic Commissions of UNESCO, Paris, p 19-22

Yasumoto T, Murata M, Oshima Y, Sano M, Matsumoto GK, Clardy J (1985) Diarrhetic shellfish toxins. Tetrahedron 41: 1019-1025

Submitted: November 12, 2009; Accepted: March 15, 2010

Proofs received from author(s): May 31, 2010 